\title{
Continuous pressurized extraction versus electric fields-assisted extraction of cyanobacterial pigments
}

\author{
Fernando Pagels ${ }^{\mathrm{a}, \mathrm{b}, \mathrm{c}, *}$, Ricardo N. Pereira ${ }^{\mathrm{c}}$, Helena M. Amaro ${ }^{\mathrm{a}}$, Vítor Vasconcelos ${ }^{\mathrm{a}, \mathrm{b}}$, \\ A. Catarina Guedes ${ }^{a}$, António A. Vicente ${ }^{\text {, } * *}$ \\ ${ }^{\text {a } C I I M A R ~-~ I n t e r d i s c i p l i n a r y ~ C e n t r e ~ o f ~ M a r i n e ~ a n d ~ E n v i r o n m e n t a l ~ R e s e a r c h, ~ U n i v e r s i t y ~ o f ~ P o r t o, ~ N o v o ~ E d i f i ́ c i o ~ d o ~ T e r m i n a l ~ d e ~ C r u z e i r o s ~ d e ~ L e i x o ̃ e s, ~ A v e n i d a ~ G e n e r a l ~}$ \\ Norton de Matos, $s / n$, 4450-208, Matosinhos, Portugal \\ ${ }^{\mathrm{b}}$ FCUP - Faculty of Science, University of Porto, Rua do Campo Alegre, s/n, 4169-007 Porto, Portugal \\ c $C E B$ - Centre of Biological Engineering, University of Minho, Campus de Gualtar, 4710-057, Braga, Portugal
}

\section{A R T I C L E I N F O}

\section{Keywords:}

Carotenoids

Phycobiliproteins

Cyanobiumsp.

Ohmic heating

Pressurized solvent extraction

\begin{abstract}
A B S T R A C T
Cyanobacteria pigments, in special carotenoids and phycobiliproteins, are usually used in industry as raw extracts, although there is still no standard methodology for their extraction. For the co-extraction of carotenoids and phycobiliproteins from the marine cyanobacterium Cyanobium sp., a continuous pressurized solvent extraction (CPSE) system and an electric fields-assisted extraction system based in ohmic heating were optimized using Central Composite Designs, with three factors each: time $(t)$, temperature $(T)$ and, flow $(f)$ for CPSE; and time, temperature and frequency $(F)$ for ohmic heating. The content of pigments and the antioxidant capacity of extracts were evaluated. All tested factors seem to influence the extraction of pigments in different ways: a high temperature $\left(70^{\circ} \mathrm{C}\right)$ had a positive impact on the extraction rate in both methods, while the influence of time depended on the extraction principle. Flow and frequency affected directly the extraction efficiency and these methods are indeed suitable for cyanobacterial pigments extraction, achieving good extraction results. Optimal conditions for co-extraction of carotenoids and phycobiliproteins in CPSE were $T=70{ }^{\circ} \mathrm{C}, t=20 \mathrm{~min}$ and $f=1.5$ $\mathrm{mL} \mathrm{min}^{-1}$, and for ohmic heating they were $T=70^{\circ} \mathrm{C}, t=5 \mathrm{~min}$ and $F=20 \mathrm{kHz}$. Both, CPSE and ohmic heating systems allowed obtaining better extraction yields when compared with a previously optimized extraction method (homogenization), used here as a reference. However, ohmic heating was the best methodology for pigments co-extraction from Cyanobium sp.
\end{abstract}

\section{Introduction}

Pigments from natural sources, such as cyanobacteria, have been seen with a great interest for industrial application due to their bioactive potential and their green product label (Mehta et al., 2018). Three natural pigments from microalgae and cyanobacteria are currently known as successful cases for market applications: phycocyanin from the cyanobacterium Arthrospira platensis (Spirulina), $\beta$-carotene from the microalgae Dunaliella salina and astaxanthin from Haematococcus pluvialis (Dufossé et al., 2005).

Natural pigments are usually commercialized as pigment-rich extracts, once the purification process increases the cost of production (Molina-Grima et al., 2003). The extraction of pigments is based on cell disruption methodologies and chemical solubility of compounds, sometimes with the use of pre-treatments with different method$\mathrm{s} /$ solvents. In the chemical industry, traditional solvent extraction is still used, although it requires a large amount of solvents that might be incompatible with the current eco-friendly thinking of the market (Iqbal and Theegala, 2013).

Associated with solvent extraction, different systems have been used to extract pigments, such as sonication, homogenization, microwave, glass beads-assisted, enzymatic or $\mathrm{CO}_{2}$ supercritical fluid extraction. However, many of them are either inefficient on large scale, hard to scale-up and/or too expensive for the natural compounds industry (Guedes et al., 2013; Pagels et al., 2019). These are the main reasons to search for new alternatives for the extraction of cyanobacteria-based

\footnotetext{
* Corresponding author at: CIIMAR - Interdisciplinary Centre of Marine and Environmental Research, University of Porto, Novo Edifício do Terminal de Cruzeiros de Leixões, Avenida General Norton de Matos, s/n, 4450-208, Matosinhos, Portugal.

** Corresponding author.

E-mail addresses: fernandopagels@gmail.com (F. Pagels), avicente@deb.uminho.pt (A.A. Vicente).
} 
products that can also bring value and market interest to these products. Among the available alternatives, high-pressure-based and electric field systems have attracted attention in the last few years (Geada et al., 2018).

The use of thermal pressurized systems has been suggested for the extraction of natural compounds, as in the case of pressurized liquid extraction (PLE) and continuous pressurized solvent extraction (CPSE). PLE systems work by injecting the solvent under pressure through the biomass, which improves the rate of extraction. However, the cost of application of PLE is still high and the use of high temperatures and pressures in thermosensitive compounds, such as pigments, may cause their degradation (Herrero et al., 2013). On the other hand, the CPSE system, designed by Amaro et al. (2018), provides a more economical and environmentally-friendly approach, increasing the extraction of pigments in more suitable conditions (lower temperatures and pressures than PLE). CPSE has also the advantage of an easier recovery and possible reuse of the extract, as the biomass is retained in the extraction chamber.

In the case of electro-based systems, ohmic heating is one of the most promising extraction methods, already used in food processing (Sastry et al., 2014; Varghese et al., 2014), although its use for pigment extraction is yet scarcely explored. Ohmic heating uses an alternating electrical current passing through a matrix (solvent + biomass) causing an internal heat dissipation (Joule effect) that can enhance the extraction process (Pereira et al., 2016; Jesus et al., 2020). The main advantages of ohmic heating are related to the uniformity of heating, highly controllable heating rate, cost and energy efficiency (Sastry et al., 2014).

This work aims at optimizing and comparing two prospective extraction methodologies (CPSE and ohmic heating) for co-extraction of carotenoids and phycobiliprotein from the cyanobacterium Cyanobium sp. in a biorefinery perspective.

\section{Material and methods}

\subsection{Cyanobacterial biomass source}

Cyanobium sp. LEGE 06113 was obtained from Blue Biotechnology and Ecotoxicology Culture Collection (LEGE-CC) and grown under an already optimized two-phase batch system (Pagels et al., 2020a), using 10 days of white LED, followed by 4 days of red LED with a light intensity of $200 \mu \mathrm{mol}_{\text {photons }} \mathrm{m}^{-2} \mathrm{~s}^{-1}$ and a light:dark cycle of 16:8 h. A modified Blue Green (BG11) medium was used with final concentrations of $\mathrm{NaCl}\left(10 \mathrm{~g} \mathrm{~L}^{-1}\right), \mathrm{NaNO}_{3}\left(3 \mathrm{~g} \mathrm{~L}^{-1}\right), \mathrm{NaHCO}_{3}\left(0.1 \mathrm{~g} \mathrm{~L}^{-1}\right)$ and $\mathrm{K}_{2} \mathrm{HPO}_{4}(0.1$ $\mathrm{g} \mathrm{L}^{-1}$ ), and $\mathrm{pH}$ set at 9.0 and kept constant with 2-(cyclohexylamino) ethanesulfonic acid (CHES)-buffer $\left(2 \mathrm{~g} \mathrm{~L}^{-1}\right.$ ) (Allen, 1968; Pagels et al., 2020b). Constant airflow was also assured at $0.75 \mathrm{Lair}^{-1} \mathrm{~min}^{-1}$. Biomass was harvested after 14 days through centrifugation (10 min, $4000 \mathrm{~g}$ ), and freeze-dried.

\subsection{Experimental design}

Aiming an optimizing pigments extraction from Cyanobium sp., two distinct methodologies were chosen (Fig. 1). The first (Fig. 1A), corresponding to a continuous pressurized solvent extraction system (CPSE) (Amaro et al., 2018) and the second (Fig. 1B), electric fields-assisted extraction system based on ohmic heating (Pereira et al., 2016). Both extractions were performed in a successive way, first, for the extraction of carotenoids (ethanol, $96 \%$ ) and then, for phycobiliproteins (water), as previously described for Cyanobium sp. (Pagels et al., 2020c).

Continuous pressurized extraction (CPSE) was set up with highperformance liquid chromatography (HPLC) solvent injection pump (Hitachi L-2130, Tokyo, Japan; 0.1-10 $\mathrm{mL} \mathrm{min}^{-1}$ and 0-360 bar); an extraction hollow column filled with cyanobacterial biomass and an excipient (Ottawa sand); and a temperature-controlled dry oven.

Ohmic heating was set up with a function generator (Agilent 33, 220 A, Bayan Lepas, Malaysia; $1 \mathrm{~Hz}-25 \mathrm{MHz}$ and 1-10 V) connected to an amplifier system (Peavey CS3000, Meridian, MS, USA; $0.3 \mathrm{~V}-170 \mathrm{~V}$ ). The temperature was recorded with a type-K thermocouple (Omega Engineering, Inc., Stamford, CT, USA), placed at the centre of the sample mixture and connected to a data logger (USB-9161, National Instruments Corporation, Austin, TX, USA). Electrical frequency, voltage and current intensity during ohmic heating treatments were measured with a portable oscilloscope (ScopeMeter ${ }^{\circledR}$ 125/S, 128 Fluke, Everett, WA, USA).

The extraction was performed with $100 \mathrm{mg}$ of dry biomass in $10 \mathrm{~mL}$ of ethanol (96\%) (carotenoids-targeted extract) and each extraction methods was applied. The biomass remaining after the extraction method was resuspended in $10 \mathrm{~mL}$ of water (phycobiliproteins-targeted extract), homogenized using a vortex and centrifuged (10 min; $2000 \mathrm{~g}$ ). For the ohmic heating method, the conductivity of the mixture biomass + solvent was set at ca. $1000 \mu \mathrm{S} . \mathrm{cm}^{-1}$ using a NaCl $20 \%$ solution $(10 \mu \mathrm{L}$ $\mathrm{mL}^{-1}$ ).

The optimization was carried out using two factorial Central Composite Design (Montgomery, 2017) matrices, with three factors each, being two in common (time ( $t$, from 5 to $20 \mathrm{~min}$ ) and temperature ( $T$, from 30 to $70{ }^{\circ} \mathrm{C}$ )) in addition to one specific to the methodology (flow ( $f$, from 1 to $4 \mathrm{~mL} \mathrm{~min}^{-1}$ ) for CPSE and frequency ( $F$, from 2 to $20 \mathrm{kHz}$ ) for ohmic heating). Factor levels were chosen in the widest range possible (Table 1), taking into account previous studies, equipment limitations (for flow and frequency levels) and the boiling point of ethanol (for temperature).

The design and models were created and analysed in the DesignExpert 9.0 software (Stat-Ease, Inc., USA). In total, 15 design points were performed in triplicate for each method, and a quadratic model was determined for each measured parameter: total carotenoids, total phycobiliproteins and antioxidant capacity (from both carotenoidstargeted extract and phycobiliproteins-targeted extract).
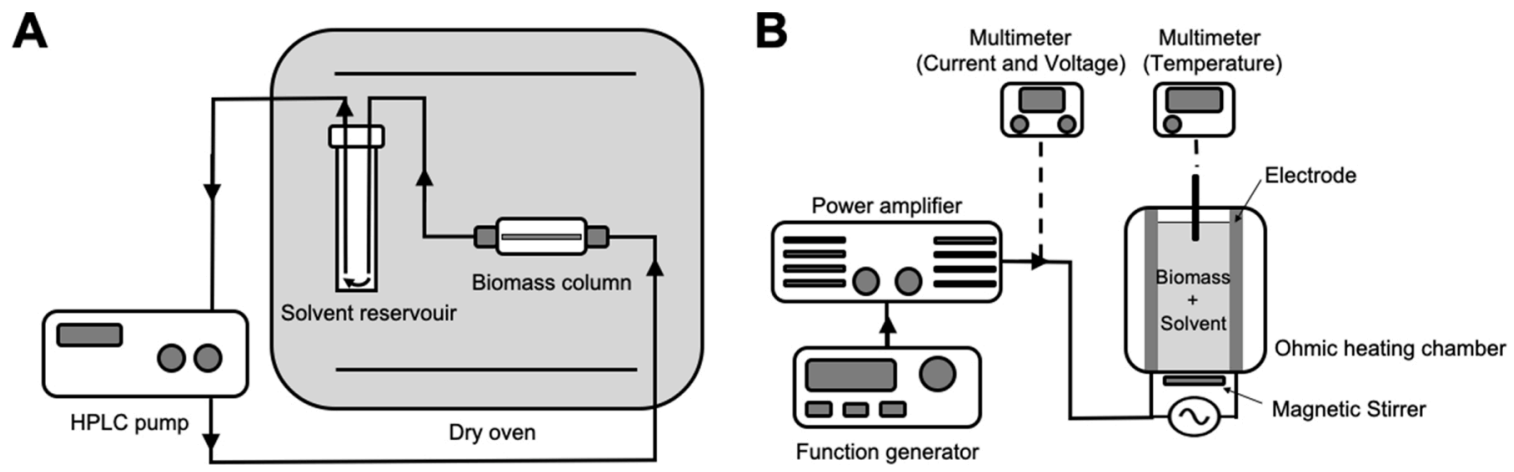

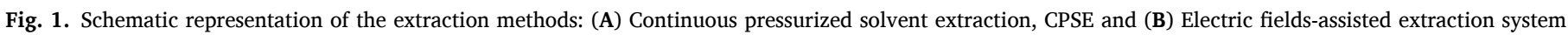
based in ohmic heating. 
Table 1

Central composite design matrix for continuous pressurized solvent extraction (CPSE) and ohmic heating, with the respective three factors: time, temperature, and flow (specific to CPSE) or frequency (specific to ohmic heating).

\begin{tabular}{|c|c|c|c|c|c|}
\hline \multirow{2}{*}{ Factor } & \multicolumn{5}{|c|}{ Coded equivalent } \\
\hline & $-\alpha$ & -1 & 0 & +1 & $+\alpha$ \\
\hline \multicolumn{6}{|c|}{ CPSE \& Ohmic Heating } \\
\hline Time (min) & 3 & 5 & 12 & 20 & 22 \\
\hline Temperature $\left({ }^{\circ} \mathrm{C}\right)$ & 26 & 30 & 50 & 70 & 74 \\
\hline \multicolumn{6}{|l|}{ CPSE } \\
\hline Flow $\left(\mathrm{mL} \min ^{-1}\right)$ & 0.7 & 1 & 2.5 & 4.0 & 4.3 \\
\hline \multicolumn{6}{|l|}{ Ohmic Heating } \\
\hline Frequency (kHz) & 0.1 & 2 & 11 & 20 & 22 \\
\hline
\end{tabular}

\subsection{Pigments quantification}

For the factorial design, pigments were quantified spectrophotometrically. Ethanolic extracts were evaluated in terms of total carotenoids, following Zavřel et al. (2015) using ethanol as blank, while water extracts were evaluated in terms of total phycobiliproteins, following Bennett and Bogorad (1973), using water as blank. The results were expressed in milligrams per gram of dry biomass ( $\mathrm{mg} \mathrm{g}_{\mathrm{DWW}}^{-1}$ ).

Total Carotenoids $(\mathrm{TC})=\left(1000 \mathrm{~A}_{470}-37.02 \mathrm{~A}_{664}\right) / 221$

Phycocyanin $(\mathrm{PC})=\left(\mathrm{A}_{615}-\left(0.474 \mathrm{~A}_{652}\right)\right) / 5.34$

Allophycocyanin $(\mathrm{APC})=\left(\mathrm{A}_{652}-\left(0.208 \mathrm{~A}_{615}\right)\right) / 5.09$

Total Phycobiliproteins $(\mathrm{TBP})=\mathrm{PC}+\mathrm{APC}$

\subsection{Antioxidant capacity}

The antioxidant capacity of the extract was evaluated, in triplicate, via the $\mathrm{ABTS}^{+}$assay as described elsewhere, using water as the solvent for the reagent (Granados-Guzmán et al., 2017). A calibration curve with Trolox was established for the quantification of the antioxidant capacity. Results are expressed as Trolox equivalents (TE) per grams of extract $\left(\mathrm{mg}_{\mathrm{TE}} \mathrm{g}_{\mathrm{DW}}^{-1}\right)$.

\subsection{Methods validation}

To validate experimentally the quadratic models obtained, the optimal condition for carotenoids and phycobiliproteins in each method (CPSE and ohmic heating) was performed. As a concept proof and for comparison between methods, a classical extraction was performed using the previous methodology described for Cyanobium sp. (Pagels et al., 2020c). The extraction was done using a homogenizer using a Precellys Evolution ( 6 series of $8000 \mathrm{rpm}$ for $30 \mathrm{~s}$ with $45 \mathrm{~s}$ of pause) using ethanol (96\%) as solvent. The remaining biomass was resuspended in $10 \mathrm{~mL}$ of water, homogenized using a vortex and centrifuged (10 min; $2000 \mathrm{~g}$ ). For comparison between the three extraction methods, carotenoids, phycobiliproteins, and antioxidant capacity assays were performed as described before. The purity of phycobiliproteins was calculated as described by Boussiba and Richmond (1979), using the formulas:

$\mathrm{P}_{\mathrm{PC}}=\left(\mathrm{A}_{615} / \mathrm{A}_{280}\right)$

$\mathrm{P}_{\mathrm{APC}}=\left(\mathrm{A}_{652} / \mathrm{A}_{280}\right)$

The profile of carotenoids was also assessed through HPLC characterization. Dried ethanolic extracts were resuspended in acetone:acetonitrile (9:1), containing $\beta$-apo-carotenol as internal standard (170 mg $\mathrm{L}^{-1}$, Sigma). The carotenoids profile was determined by HPLC with photodiode array (PDA) detection (Waters Alliance 2695, USA), following a method previously described by Guedes et al. (2011) using carotenoids standards for calibration curves (peak area $(y) v s$. concentration $(x))$ : Lutein $\left(y=51697^{*} \mathrm{x}-165095 ; \mathrm{R}^{2}=0.99\right)$, Zeaxanthin $(y=$ $\left.1085021 * x-382196 ; R^{2}=0.99\right), \beta$-carotene $(y=151970 * x-670343$; $\left.\mathrm{R}^{2}=0.99\right)$ and Echinenone $(\mathrm{y}=38404 * \mathrm{x}-26680$; $\mathrm{R} 2=0.99)$. The results were expressed in terms of milligrams of carotenoids per gram of dry biomass (mg gDW).

\subsection{Statistical analysis}

Significance levels for each evaluated parameter were obtained by the analysis of variance (ANOVA), using Design-Expert 9.0 software. Also, a lack-of-fit test was applied to compare the residues of the model and the observed results. The model is validated whenever the statistical significance was higher than 0.05 in the lack-of-fit test.

Comparison between the extraction methods was analysed using GraphPad Prism v.7 software (GraphPad, USA). Each data set homoscedasticity was verified by Cochran's test. One-way ANOVA was used for all tested parameters. Whenever significant differences were detected, posthoc multiple comparisons were made using the Newman-Keuls test to identify differences for the conditions. The significance level in all cases was $95 \%(p<0.05)$. The number of replicates for all parameters was three $(n=3)$.

\section{Results and discussion}

\subsection{Factorial design}

\subsubsection{Continuous pressurized solvent extraction (CPSE)}

The optimization of the CPSE method through a central composite design resulted in significant quadratic models $(p<0.01)$ for all the studied parameters (Table 2). The models suggest as optimal condition for co-extraction of carotenoids followed by phycobiliproteins the following combination of variables: $\boldsymbol{T}=\mathbf{7 0}{ }^{\circ} \mathrm{C}, t=20 \mathrm{~min}$ and $f=\mathbf{1 . 5}$ $\mathrm{mL} \mathrm{min}^{-1}$. Temperature, time and flow influenced the studied parameters and different trends were found for the different targeted products. The response surface plot for each studied parameter is depicted in Fig. 2.

In this system, solvent flow is directly related to the applied pressure on the biomass (ca. 110 bar for $1.5 \mathrm{~mL} \mathrm{~min}^{-1}$ ) and extraction time is related to the number of recirculations of the solvent into the biomass column, for example, $20 \mathrm{~min}$ of extraction at $2 \mathrm{~mL} \mathrm{~min}^{-1}$ represents 4 cycles of solvent recirculation.

From the model coefficients and surface plots, it is evident that an increase in the temperature leads to a higher extraction rate. In the case

Table 2

Model analyses for continuous pressurized solvent extraction (CPSE) central composite design in the measured parameters: total carotenoids, total phycobiliproteins and antioxidant capacity (AOX) for ethanolic and water extracts. The quadratic model is set for temperature $(T)$, time $(t)$ and flow $(f)$ in actual values.

\begin{tabular}{|c|c|c|c|}
\hline Parameter & $\begin{array}{l}p- \\
\text { value }\end{array}$ & $\mathrm{R}^{2}$ & Quadratic model \\
\hline Carotenoids (mg g gW) & $<0.01$ & 0.95 & $\begin{array}{l}-12.42+1.48 T-0.45 t+5.99 f+ \\
0.02 T t-0.02 T f+0.13 t f-0.01 T^{2}-0.02 \\
t^{2}-1.50 f^{2}\end{array}$ \\
\hline $\begin{array}{l}\text { Phycobiliproteins (mg } \\
\mathrm{g}_{\mathrm{DW}}^{-1} \text { ) }\end{array}$ & $<0.01$ & 0.94 & $\begin{array}{l}110.02-1.91 T-7.17 t+58.28 f+ \\
0.07 T t-0.49 T f-0.84 t f+0.02 T^{2}+0.21 \\
t^{2}-5.20 f^{2}\end{array}$ \\
\hline $\begin{array}{l}\text { AOX - Ethanolic } \\
\left(\mathrm{mg}_{\mathrm{TE}} \mathrm{g}_{\mathrm{DW}}^{-1}\right)\end{array}$ & $<0.01$ & 0.90 & $\begin{array}{l}0.225+0.055 T+0.608 t+1.424 f- \\
0.008 T t-0.0001 T f-0.088 t f+ \\
0.0002 T^{2}-0.004 t^{2}+0.079 f^{2}\end{array}$ \\
\hline $\begin{array}{l}\text { AOX - Water }\left(\mathrm{mg}_{\mathrm{TE}}\right. \\
\left.\mathrm{g}_{\mathrm{DW}}^{-1}\right)\end{array}$ & $<0.01$ & 0.70 & $\begin{array}{l}2.303-0.050 T-0.130 t+0.742 f+ \\
0.008 T t-0.006 T f-0.004 t f+0.0006 T^{2} \\
+0.004 t^{2}-0.061 f^{2}\end{array}$ \\
\hline
\end{tabular}


A

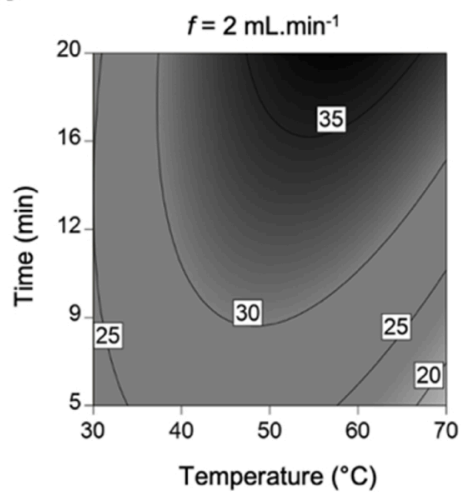

B

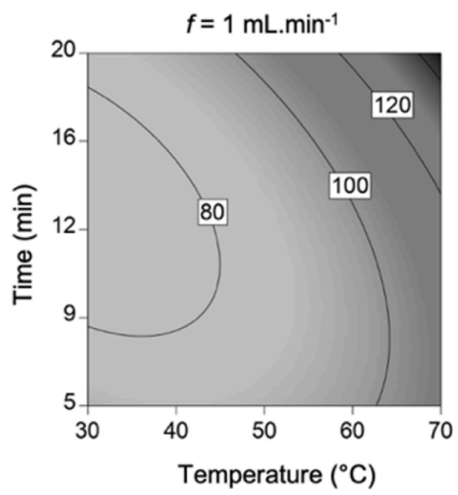

C

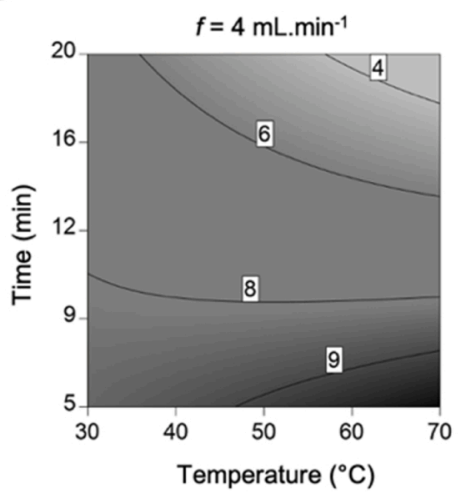

D

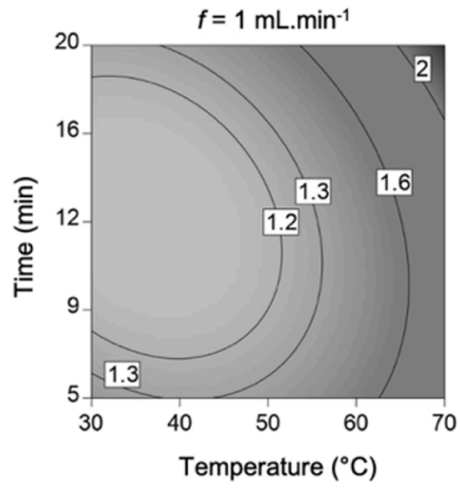

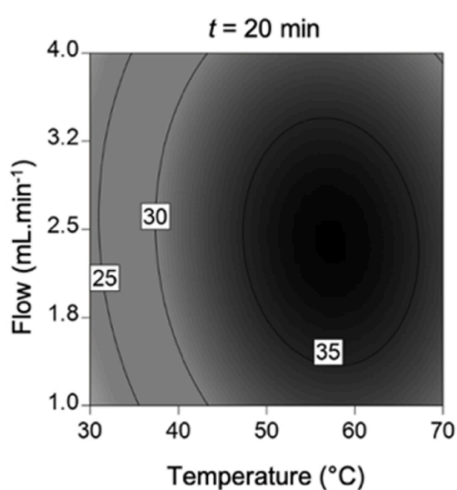
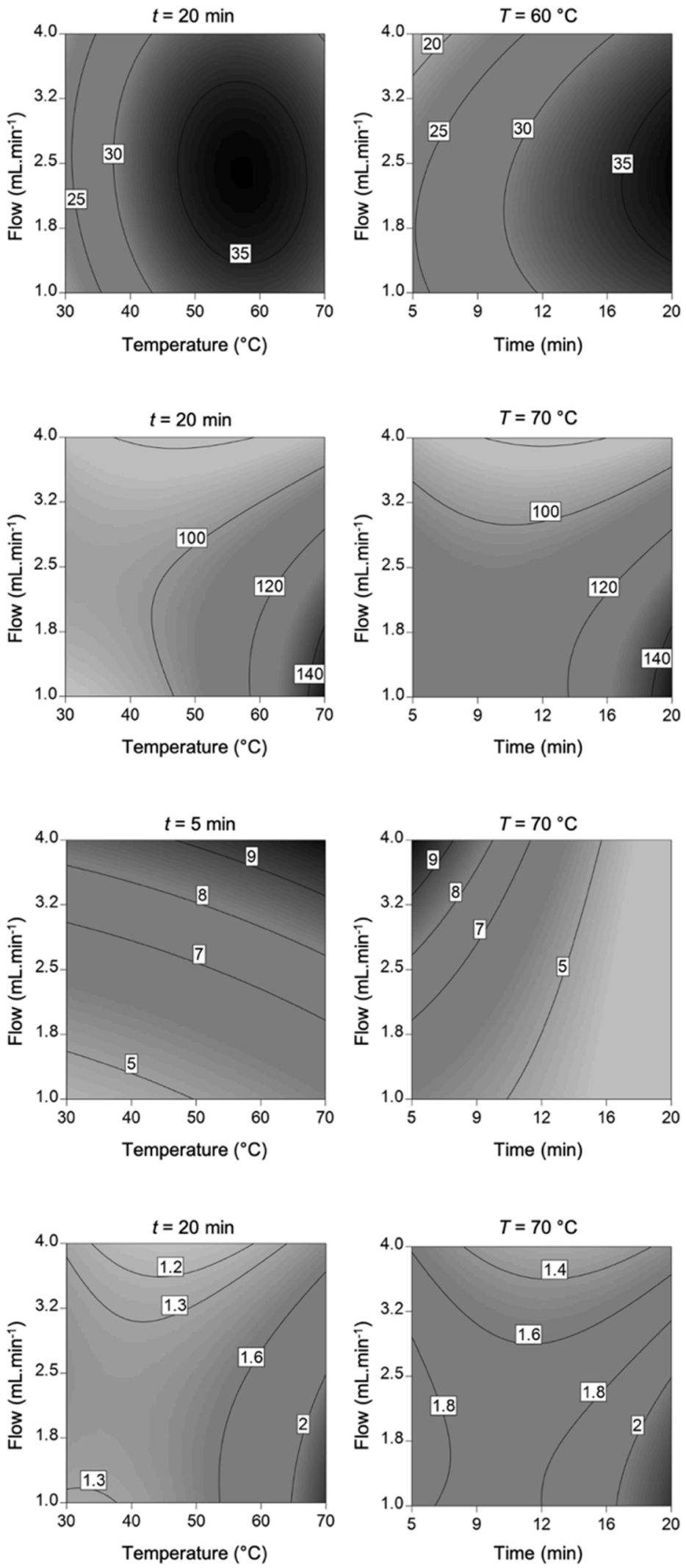

Fig. 2. Response surface plots for temperature (T), time $(t)$ and flow ( $f$ ) of continuous pressurized solvent extraction (CPSE), showing (A) Total Carotenoids (mg $g_{\text {DW }}^{-1}$ ) (B) Total Phycobiliproteins ( $\mathrm{mg} \mathrm{g}_{\mathrm{DW}}^{-1}$ ); (C) Antioxidant Capacity - Ethanolic extracts (mg $\mathrm{T}_{\mathrm{TE}} \mathrm{g}_{\mathrm{DW}}^{-1}$ ) and (D) Antioxidant Capacity - Water extracts (mg graph is set in the optimal level of the factor not included in the axis. 
of carotenoids (Fig. 2A), the carotenoids' optimized concentration range was from 9.59 to $36.83 \mathrm{mg} \mathrm{g} \mathrm{gW}^{-1}$ and in spite being thermosensitive components (Guedes et al., 2013; Amaro et al., 2018), carotenoids resisted the highest temperature tested. These findings go in a similar trend to previous studies of extraction of carotenoids, as seen in supercritical fluid extraction of carotenoids from the microalga Scenedesmus obliquus that increased the yield by increasing the temperature from 40 ${ }^{\circ} \mathrm{C}$ to $60{ }^{\circ} \mathrm{C}$ (Guedes et al., 2013), and the extraction of the cyanobacterium Gloeothece sp. also using CPSE, which yielded an optimal temperature of $60^{\circ} \mathrm{C}$, flow at $2 \mathrm{~mL} \mathrm{~min}^{-1}$ and 3 cycles of extraction (Amaro et al., 2018).

On the other hand, for the subsequent extraction of phycobiliproteins (Fig. 2B), the tested conditions described above can be seen as a pretreatment, once the water needed to perform this part of the extraction does not go through the system, and it is only added to the biomass that remains after carotenoids extraction, described above. The optimized concentration range, in the case of phycobiliproteins, varied from 64.73-159.68 $\mathrm{mg} \mathrm{g}_{\mathrm{DW}}^{-1}$. Higher values of phycobiliprotein for high temperature and longer time of extraction indicate that the use of these settings means a better cleaning of the biomass, followed by a better water extraction in the remaining pellet. In terms of flow, using these higher values of $T$ and $t$, a lower flow is required in the system to avoid degradation of the biomass. If the flow is set at $4 \mathrm{~mL} \mathrm{~min}^{-1}$, the temperature must be decreased to $30{ }^{\circ} \mathrm{C}$ to maintain a relatively high extraction rate.

Moreover, the antioxidant capacity of ethanolic (Fig. 2C) and water (Fig. 2D) extracts is usually related to carotenoids and phycobiliproteins - respectively - and a Pearson correlation was attempted for the antioxidant capacity of both extracts and the pigment content in the respective extract. A poor correlation was found between the antioxidant capacity of ethanolic extract and carotenoids content $\left(p=0.002 ; \mathrm{R}^{2}\right.$ $=0.53$ ), on the other hand, a good correlation was found between the antioxidant capacity of water extracts and phycobiliproteins $(p<0.001$; $\mathrm{R}^{2}=0.90$ ). The poor correlation between the antioxidant capacity of ethanolic extracts and the pigment content might be due to interaction with other kinds of antioxidant compounds (e.g. phenolic compounds and fatty acids). The optimized concentration range for antioxidant capacity of ethanolic and water extracts was 1.86-10.16 mg $\mathrm{TE}_{\mathrm{TE}} \mathrm{g}_{\mathrm{DW}}^{-1}$ and $0.65-2.44 \mathrm{mg}_{\mathrm{TE}} \mathrm{g}_{\mathrm{DW}}^{-1}$, respectively.

\subsubsection{Ohmic heating}

The optimization of electric fields-assisted extraction system based on ohmic heating through a central composite design also provided a significant quadratic model $(p<0.01)$ for all the studied parameters (Table 3). Temperature, time and frequency influence in the parameters can be seen in the response surface plot for each parameter as depicted in Fig. 3.

\section{Table 3}

Model analyses for ohmic heating central composite design in the measured parameters: total carotenoids, total phycobiliproteins and antioxidant capacity (AOX) for ethanolic and water extracts. The quadratic model is set for temperature $(T)$, time $(t)$ and frequency $(F)$ in actual values.

\begin{tabular}{|c|c|c|c|}
\hline Parameter & $\begin{array}{l}p \\
\text { value }\end{array}$ & $\mathrm{R}^{2}$ & Quadratic model \\
\hline Carotenoids (mg g g & $<0.01$ & 0.95 & $\begin{array}{l}16.850+0.699 T-0.354 t+0.906 F+ \\
0.002 T t+0.003 T F-0.013 t F-0.006 T^{2} \\
+0.013 t^{2}-0.031 F^{2}\end{array}$ \\
\hline $\begin{array}{l}\text { Phycobiliproteins (mg } \\
\text { gDW) }^{-1} \text { ) }\end{array}$ & $<0.01$ & 0.86 & $\begin{array}{l}125.097-0.060 T+3.983 t-4.211 F- \\
0.018 T t+0.037 T F-0.019 t F-0.002 T^{2} \\
-0.127 t^{2}+0.127 F^{2}\end{array}$ \\
\hline $\begin{array}{l}\text { AOX - Ethanolic } \\
\left(\mathrm{mg}_{\mathrm{TE}} \mathrm{g}_{\mathrm{DW}}^{-1}\right)\end{array}$ & $<0.01$ & 0.91 & $\begin{array}{l}14.491-0.141 T-0.358 t-0.123 F+ \\
0.001 T t+0.002 T F+0.005 t F+0.001 T^{2} \\
+0.009 t^{2}-0.003 F^{2}\end{array}$ \\
\hline $\begin{array}{l}\text { AOX - Water }\left(\mathrm{mg}_{\mathrm{TE}}\right. \\
\left.\mathrm{g}_{\mathrm{DW}}^{-1}\right)\end{array}$ & $<0.01$ & 0.97 & $\begin{array}{l}0.155+0.469 T+0.424 t-0.715 F- \\
0.003 T t+0.009 T F+0.006 t F-0.005 T^{2} \\
-0.013 t^{2}+0.012 F^{2}\end{array}$ \\
\hline
\end{tabular}

For a co-extraction of carotenoids followed by phycobiliproteins, the optimal conditions correspond to the following combination of variables: $\mathbf{T}=\mathbf{7 0}{ }^{\circ} \mathbf{C}, \boldsymbol{t}=\mathbf{5} \mathrm{min}$ and $\boldsymbol{F}=\mathbf{2 0} \mathbf{~ k H z}$. The use of a higher temperature leads to an effect similar to the one found in CPSE, while the electric fields seem to affect the time of extraction, demanding a reduced time to prevent pigment degradation.

Regarding the extraction trend for carotenoids (Fig. 3A), high temperature and high frequency induce the extraction of a higher content of carotenoids. Temperature guided extraction has been described as successful for the obtention of carotenoids with ohmic heating (Coelho et al., 2019). However, Aguilar-Machado et al. (2017) suggest that degradation of pigments occurs under higher temperatures $\left(>70{ }^{\circ} \mathrm{C}\right)$, depending on the time of extraction. The carotenoids' optimized concentration range was from 31.48 to $42.92 \mathrm{mg} \mathrm{g} \mathrm{g}_{\mathrm{DW}}^{-1}$. When comparing these values with those obtained with CPSE, it seems that the use of ohmic heating, overall, leads to a higher extraction of carotenoids.

In the case of the extraction of phycobiliproteins (Fig. 3B), the efficacy of the pre-treatment seems to be also more affected by frequency and temperature, and similarly to CPSE, the increase of temperature induces a more efficient extraction with ethanol, leading to a higher extraction of phycobiliproteins in the remaining pellet. The optimized concentration range for phycobiliproteins was from 107.28-146.34 $\mathrm{mgg}_{\mathrm{DW}}^{-1}$, a shorter range than in CPSE.

The use of higher frequencies on cyanobacterial pigments goes in a contradictory way when compared to microalgae and plants biomass extraction. Usually, a lower frequency leads to a higher extraction due to electroporation (Yodsuwan et al., 2018), although it has been reported that specific membranes of cells might need a higher frequency treatment (Asavasanti et al., 2010). The advantage of a frequency higher than $1 \mathrm{kHz}$ is the absence of corrosion on the electrodes (Tola et al., 2014; Pataro et al., 2014). In the case of Cyanobium sp. a higher frequency associated with a higher temperature induced probably to a higher cell disruption caused by electrical and thermal effects, leading to better extraction of both carotenoids and phycobiliproteins (Geada et al., 2018). On the contrary, at lower temperature and frequency, the reported effect of electroporation (Yodsuwan et al., 2018) may have promoted better extraction of phycobiliproteins in the successive extraction, although the lower temperature reduces the extraction of carotenoids (Cheng et al., 2020). These results may indicate that the thermal process seems to favour extraction of carotenoids while electric effects seem to enhance extraction of phycobiliproteins.

Regarding antioxidant capacity, no correlation was found between the antioxidant capacity of ethanolic extracts and the total carotenoids content ( $\left.p=0.76 ; \mathrm{R}^{2}=0.006\right)$, again, the antioxidant capacity might be related not only to carotenoids but to polyphenols and fatty acids in a synergetic way. On the other hand, a positive correlation was found between the antioxidant capacity of water extracts and the total phycobiliproteins content $\left(p<0.001 ; \mathrm{R}^{2}=0.91\right)$, meaning that phycobiliproteins have a great impact on the antioxidant capacity of water extracts. The optimized concentration range varied from 6.68 to 10.26 $\mathrm{mg}_{\mathrm{TE}} \mathrm{g}_{\mathrm{DW}}^{-1}$ for the ethanolic extract (Fig. 3C) and 1.90-12.33 $\mathrm{mg}_{\mathrm{TE}} \mathrm{g}_{\mathrm{DW}}^{-1}$ for water extracts (Fig. 3D). The values were overall higher with ohmic heating extraction when compared to the ones found with CPSE.

\subsection{Model validation and extraction method selection}

To validate the optimization of CPSE and ohmic heating extraction methods, the optimal condition for co-extraction of carotenoids and phycobiliproteins was assessed for both methods. The predicted and observed values for both optimized systems are detailed in Table 4. All models were validated since predicted and observed values were statistically identical $(p>0.05)$. Furthermore, a comparison was established between the optimized methods and a homogenization extraction (described and optimized in a previous publication: see Pagels et al., 2020c), which was used as a reference (Table 4).

Regarding carotenoids, ohmic heating extraction led to the highest 
A
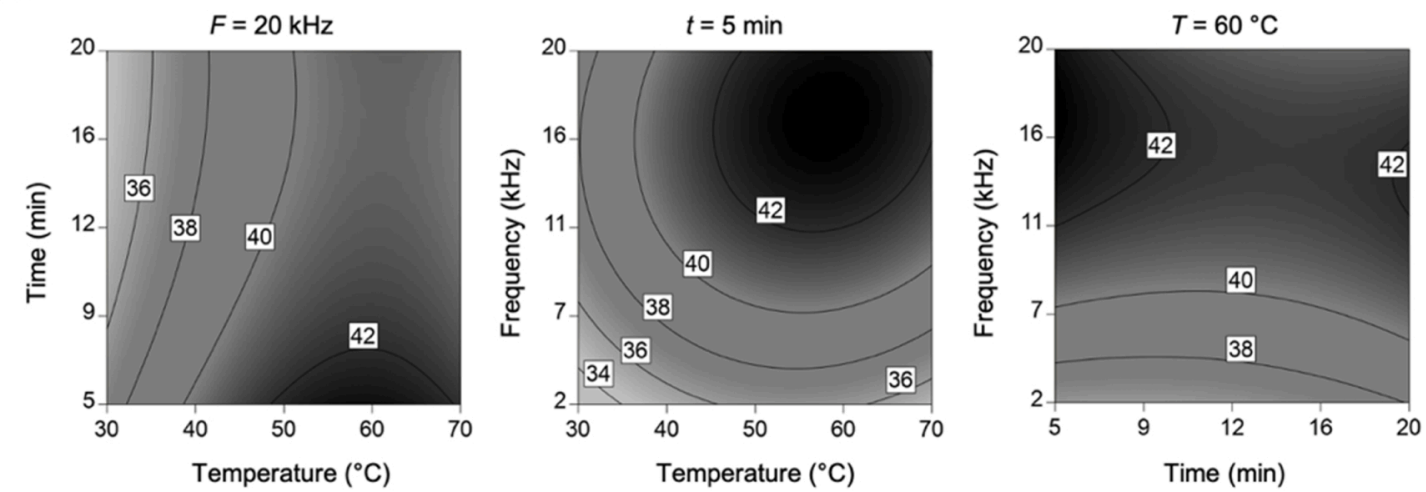

B
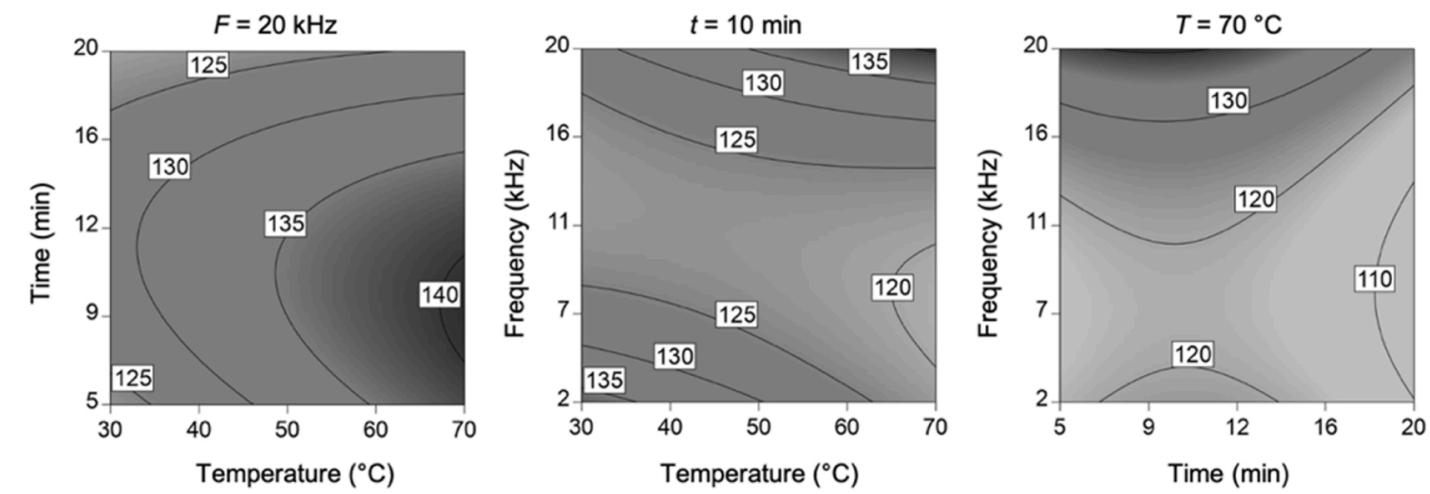

C
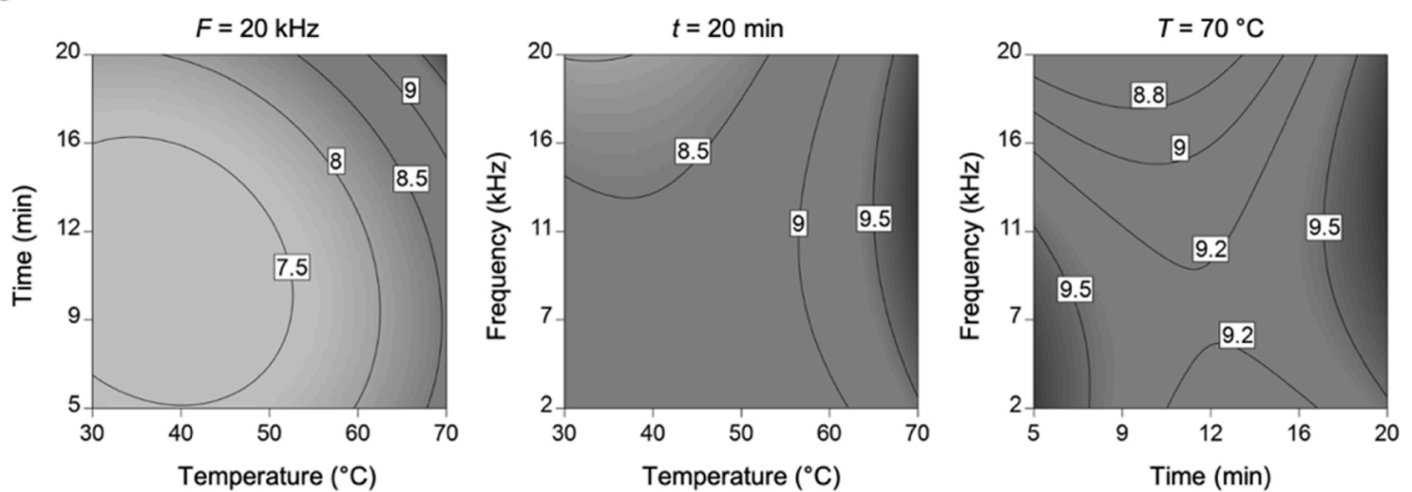

D
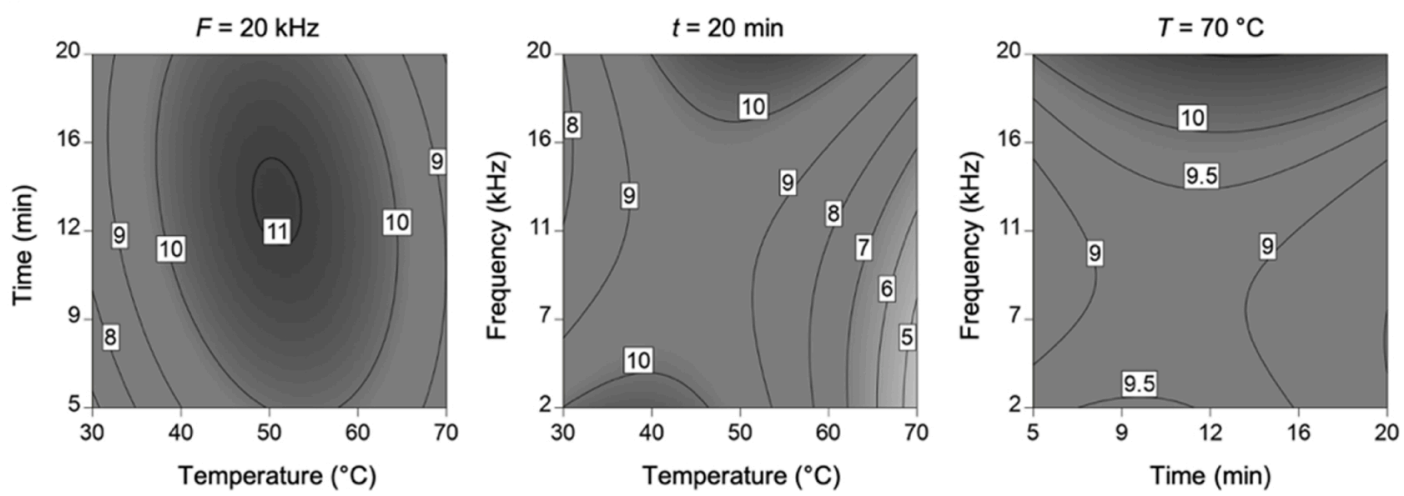

Fig. 3. Response surface plots for temperature $(T)$, time $(t)$ and frequency $(F)$ of ohmic heating extraction (OH), showing (A) Total Carotenoids (mg gDW $(B)$ Total Phycobiliproteins ( $\left.\mathrm{mg} \mathrm{g}_{\mathrm{DW}}^{-1}\right)$; (C) Antioxidant Capacity - Ethanolic extracts $\left(\mathrm{mg}_{\mathrm{TE}} \mathrm{g}_{\mathrm{DW}}^{-1}\right.$ ) and (D) Antioxidant Capacity - Water extracts (mg $\left.\mathrm{mg}_{\mathrm{TE}} \mathrm{g}_{\mathrm{DW}}^{-1}\right)$. Each graph is set in the optimal level of the factor not included in the axis. 
Table 4

Responses for the optimal condition for the extraction based on the Central Component Design for continuous pressurized solvent extraction (CPSE) and ohmic heating $(\mathrm{OH})$. The optimized methods were compared with an optimized homogenization (H) extraction, as previously described by Pagels et al. (2020c), which was used here as a reference.

\begin{tabular}{|c|c|c|c|c|c|}
\hline \multirow{2}{*}{ Parameters } & \multicolumn{2}{|l|}{ CPSE } & \multicolumn{2}{|l|}{$\mathrm{OH}$} & \multirow{2}{*}{$\begin{array}{l}\mathrm{H} \\
\text { Observed }\end{array}$} \\
\hline & Predicted & Observed & Predicted & Observed & \\
\hline $\mathrm{TC}\left(\mathrm{mg} \mathrm{g} \mathrm{g}_{\mathrm{DW}}^{-1}\right)$ & $\begin{array}{l}32.9 \pm \\
1.6^{\mathrm{a}}\end{array}$ & $\begin{array}{l}31.6 \pm \\
1.8^{\mathrm{a}, \mathrm{A}}\end{array}$ & $\begin{array}{l}41.8 \pm \\
0.8^{\mathrm{a}}\end{array}$ & $\begin{array}{l}41.6 \pm \\
1.7^{\text {a, B }}\end{array}$ & $\begin{array}{l}30.7 \pm \\
1.9^{\mathrm{A}}\end{array}$ \\
\hline TBP (mg g $\left.\mathrm{g}_{\mathrm{DW}}^{-1}\right)$ & $\begin{array}{l}143.3 \pm \\
5.6^{\mathrm{a}}\end{array}$ & $\begin{array}{l}133.4 \pm \\
7.5^{\mathrm{a}, \mathrm{A}}\end{array}$ & $\begin{array}{l}138.5 \pm \\
4.2^{\mathrm{a}}\end{array}$ & $\begin{array}{l}136.6 \pm \\
10.0^{\mathrm{a}, \mathrm{A}}\end{array}$ & $\begin{array}{l}108.1 \pm \\
7.9^{\mathrm{B}}\end{array}$ \\
\hline $\begin{array}{l}\text { AOX - } \\
\quad \text { Ethanolic } \\
\left(\mathrm{mg}_{\mathrm{TE}} \mathrm{g}_{\mathrm{DW}}^{-1}\right)\end{array}$ & $2.7 \pm 0.7^{\mathrm{a}}$ & $\begin{array}{l}3.2 \pm \\
0.1^{\mathrm{a}, \mathrm{A}}\end{array}$ & $8.6 \pm 0.3^{\mathrm{a}}$ & 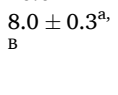 & $\begin{array}{l}6.5 \pm \\
0.6^{\mathrm{C}}\end{array}$ \\
\hline $\begin{array}{l}\text { AOX - Water } \\
\quad\left(\mathrm{mg}_{\mathrm{TE}} \mathrm{g}_{\mathrm{DW}}^{-1}\right)\end{array}$ & $2.2 \pm 0.2^{\mathrm{a}}$ & $\begin{array}{l}2.3 \pm \\
0.5^{\mathrm{a}, \mathrm{A}}\end{array}$ & $8.5 \pm 0.5^{\mathrm{a}}$ & $\begin{array}{l}8.3 \pm 0.3^{\mathrm{a}}, \\
\mathrm{B}\end{array}$ & $\begin{array}{l}6.6 \pm \\
0.6^{\mathrm{C}}\end{array}$ \\
\hline
\end{tabular}

AOX $=$ antioxidant capacity; $\mathrm{TC}=$ total carotenoids; $\mathrm{TBP}=$ total phycobiliproteins.

Different lowercase letters indicate statistically significant differences between predicted and observed values for each parameter for each method.

Different uppercase letters indicate statistically significant differences between the observed values for each parameter obtained for each of the two tested methods and the reference method.

concentration of total carotenoids of $41.59 \pm 1.71 \mathrm{mg} \mathrm{g} \mathrm{gW}^{-1}(p<0.05)$, a content 1.3-fold higher than CPSE and homogenization extraction. If considered the carotenoid profile (Table 5), the identified carotenoids lutein, zeaxanthin, echinenone and $\beta$-carotene - represent ca. $60 \%$ of total carotenoids, with similar percentages of the four identified carotenoids in all tested conditions.

In terms of total phycobiliproteins (Table 4), both novel methods extracted the same content of pigments $(p>0.05), 133.4 \pm 7.5 \mathrm{mg} \mathrm{g} \mathrm{gWW}^{-1}$ in CPSE and $136.6 \pm 10.0 \mathrm{mg} \mathrm{g}_{\mathrm{DW}}^{-1}$ in ohmic heating. This content is 1.2fold higher than homogenization $(p<0.05)$. All tested extractions had a ratio of $1: 2$ between phycocyanin and allophycocyanin. Allophycocyanin applications and bioactive properties are still less known than phycocyanin, mainly because in most cyanobacteria, phycocyanin is the main pigment present. Such phycobiliprotein profile, however, might be biotechnologically attractive as allophycocyanin have been described as an antiviral component (Shih et al., 2003). Ohmic heating extracts had higher antioxidant capacity in both ethanol and water extracts $(p<$ 0.05 ), with $8.04 \pm 0.31 \mathrm{mg}_{\mathrm{TE}} \mathrm{g}_{\mathrm{DW}}^{-1}$ and $8.33 \pm 0.31 \mathrm{mg}_{\mathrm{TE}} \mathrm{g}_{\mathrm{DW}}^{-1}$, respectively.

In terms of purity of phycobiliproteins (Table 6), in both phycocyanin and allophycocyanin, the use of a successive extraction increases the purity and phycobiliprotein concentration on the extract (Pagels et al., 2020c). Ohmic heating had the highest values of purity, ca. of 1.2-fold higher than homogenization and 1.6-fold higher than CPSE. Food grade purity of phycobiliproteins is $\geq 0.7$, and analytical purity $\geq$ 4.0 (Patil et al., 2006). The present study indicates that both CPSE and ohmic heating provides purity for food-grade applications, with no additional purification process needed.

Besides extracts yield and composition, the design and applicability of the system must be considered. In large-scale processing, homogenization is still hard to be as efficient as in lab-scale, however, in the case

\section{Table 5}

Comparison of carotenoids profile between extraction methods - continuous pressurized solvent extraction (CPSE), ohmic heating $(\mathrm{OH})$ and homogenization $(\mathrm{H})$, used as reference.

\begin{tabular}{lllll}
\hline \multirow{2}{*}{ Extraction Method } & \multicolumn{4}{l}{ Carotenoid (\%Total Carotenoids) } \\
\cline { 2 - 5 } & Lutein & Zeaxanthin & Echinenone & $\beta$-carotene \\
\hline CPSE & $13.4 \pm 0.1$ & $11.4 \pm 0.1$ & $17.2 \pm 1.1$ & $21.7 \pm 0.1$ \\
OH & $13.1 \pm 0.1$ & $13.8 \pm 0.2$ & $12.9 \pm 0.5$ & $24.5 \pm 0.3$ \\
H & $13.4 \pm 0.8$ & $14.4 \pm 0.7$ & $14.7 \pm 1.3$ & $24.8 \pm 0.9$ \\
\hline
\end{tabular}

Table 6

Comparison of phycobiliproteins purity between extraction/pre-treatment methods- ohmic heating $(\mathrm{OH})$, continuous pressurized solvent extraction (CPSE) and homogenization (H), used as reference.

\begin{tabular}{lll}
\hline Extraction Method & Phycocyanin & Allophycocyanin \\
\hline CPSE & $1.72 \pm 0.07^{\mathrm{a}}$ & $2.03 \pm 0.10^{\mathrm{a}}$ \\
OH & $2.37 \pm 0.02^{\mathrm{b}}$ & $2.77 \pm 0.08^{\mathrm{b}}$ \\
H & $2.05 \pm 0.03^{\mathrm{c}}$ & $2.38 \pm 0.03^{\mathrm{c}}$ \\
\hline
\end{tabular}

Different lowercase letters indicate statistical differences between values for each pigment for each method.

of both CPSE and ohmic heating, the design is scalable. CPSE has the advantage of an easy recovery of the ethanolic extract, once it passes through the column and is collected without any biomass. In the case of ohmic heating, an additional step of centrifugation or filtration is needed. On the other hand, ohmic heating has easier handling of biomass and can be applied continuous, while CPSE works in batches of specific amounts of biomass. Taking into account all the results obtained in this work and the subsequent discussion, it is recommended for the extraction of carotenoids, phycobiliproteins and co-extraction of the two groups of pigments with the use of ohmic heating.

\section{Conclusions}

Optimal treatment for the co-extraction of total carotenoids and phycobiliproteins was found to be $T=70^{\circ} \mathrm{C}, t=20 \mathrm{~min}$ and $f=1.5 \mathrm{~mL}$ $\min ^{-1}$ for CPSE, and $T=70{ }^{\circ} \mathrm{C}, t=5 \mathrm{~min}$ and $F=20 \mathrm{kHz}$ for ohmic heating. From the tested extraction methodologies, ohmic heating showed to be the best in terms of pigments extraction and also in terms of enhancing antioxidant capacity of both ethanolic and water extracts, being recommendable for co-extraction of carotenoids and phycobiliproteins from Cyanobium sp.. Both CPSE and ohmic heating performed better than the extraction by homogenization, used here as a reference.

\section{Author contributions}

FP, VV, ACG and AAV conceived and designed research; FP, RNP and HMA performed the experimental trials; FP, RNP and HMA performed data analysis; ACG, VV and AAV were responsible for the supervision and funding acquirement. FP wrote the paper which was revised by all authors. All authors approved the manuscript.

\section{Funding}

A PhD fellowship (reference SFRH/BD/136767/2018) for author Fernando Pagels was granted by Fundação para a Ciência e Tecnologia (FCT, Portugal) under the auspices of Programa Operacional Capital Humano (POCH), supported by the European Social Fund and Portuguese funds (MECTES). This work was financially co-supported by the strategical funding from FCT UIDB/04423/2020, UIDP/04423/2020 and UIDB/04469/2020; and the project ALGAVALOR - MicroALGAs: produção integrada e VALORização da biomassa e das suas diversas aplicaçoes (POCI-01-0247-FEDER-035234), supported by the European Regional Development Fund and BioTecNorte operation (NORTE-010145-FEDER-000004) funded by the European Regional Development Fund under the scope of Norte2020 - Programa Operacional Regional do Norte.

\section{Ethical statement}

This article does not contain any studies with human participants or animals performed by any of the authors. 


\section{Declaration of Competing Interest}

The authors declare that there is no conflict of interest regarding the publication of this article.

\section{References}

Aguilar-Machado, D., Morales-Oyervides, L., Contreras-Esquivel, J.C., Aguilar, C., Méndez-Zavala, A., Raso, J., Montañez, J., 2017. Effect of ohmic heating processing conditions on color stability of fungal pigments. Food Sci. Technol. Int. 23 (4), 338-348. https://doi.org/10.1177/1082013216689514.

Allen, M.M., 1968. Simple conditions for growth of unicellular blue-green algae on plates. J. Phycol. 4, 1-4. https://doi.org/10.1111/j.1529-8817.1968.tb04667.x.

Amaro, H.M., Guedes, A.C., Preto, M.A.C., Sousa-Pinto, I., Malcata, F.X., 2018. Gloeothece sp. As a nutraceutical source-an improved method of extraction of carotenoids and fatty acids. Mar. Drugs 16 (9), 327. https://doi.org/10.3390/md16090327.

Asavasanti, S., Ersus, S., Ristenpart, W., Stroeve, P., Barrett, D.M., 2010. Critical otal phycobiliproteins electric field strengths of onion tissues treated by pulsed electric fields. J. Food Sci. 75 (7), E433-E443. https://doi.org/10.1111/j.17503841.2010.01768.x.

Bennett, A., Bogorad, L., 1973. Complementary chromatic adaptation in a filamentous blue-green alga. J. Cell Biol. 58, 419-435. https://doi.org/10.1083/jcb.58.2.419.

Boussiba, S., Richmond, A.E., 1979. Isolation and characterization of phycocyanins from the blue-green alga Spirulina platensis. Arch. Microbiol. 120 (2), 155-159. https:// doi.org/10.1007/BF00409102.

Cheng, S.H., Khoo, H.E., Kong, K.W., Prasad, K.N., Galanakis, C.M., 2020. Extraction of carotenoids and applications. In: Galanakis, C.M. (Ed.), Carotenoids: Properties, Processing and Applications. Academic Press, USA, pp. 259-288. https://doi.org/ 10.1016/B978-0-12-817067-0.00008-7.

Coelho, M., Pereira, R., Rodrigues, A.S., Teixeira, J.A., Pintado, M.E., 2019. Extraction of tomato by-products' bioactive compounds using ohmic technology. Food Bioprod. Process. 117, 329-339. https://doi.org/10.1016/j.fbp.2019.08.005.

Dufossé, L., Galaup, P., Yaron, A., Arad, S.M., Blanc, P., Murthy, K.N.C., Ravishankar, G. A., 2005. Microorganisms and microalgae as sources of pigments for food use: A scientific oddity or an industrial reality? Trends Food Sci. Techn. 16 (9), 389-406. https://doi.org/10.1016/j.tifs.2005.02.006.

Geada, P., Rodrigues, R., Loureiro, L., Pereira, R., Fernandes, B., Teixeira, J.A., Vasconcelos, V., Vicente, A.A., 2018. Electrotechnologies applied to microalgal biotechnology-Applications, techniques and future trends. Renew. Sust. Energ. Rev. 94, 656-668. https://doi.org/10.1016/j.rser.2018.06.059.

Granados-Guzmán, G., Salazar-Aranda, R., Garza-Tapia, M., Castro-Ríos, R., Waksman de Torres, N., 2017. Optimization and validation of two high-throughput methods indicating antiradical activity. Curr. Anal. Chem. 13 (6), 499-507. https://doi.org/ 10.2174/1573411013666170118111516.

Guedes, A.C., Amaro, H.M., Pereira, R.D., Malcata, F.X., 2011. Effects of temperature and $\mathrm{pH}$ on growth and antioxidant content of the microalga Scenedesmus obliquus. Biotechnol. Prog. 27, 1218-1224. https://doi.org/10.1002/btpr.649.

Guedes, A.C., Gião, M.S., Matias, A.A., Nunes, A.V.M., Pintado, M.E., Duarte, C.M.M., Malcata, F.X., 2013. Supercritical fluid extraction of carotenoids and chlorophylls $a$, $b$ and $c$, from a wild strain of Scenedesmus obliquus for use in food processing. J. Food Eng. 116 (2), 478-482. https://doi.org/10.1016/j.jfoodeng.2012.12.015.

Herrero, M., Castro-Puyana, M., Mendiola, J.A., Ibañez, E., 2013. Compressed fluids for the extraction of bioactive compounds. Trends Analyt. Chem. 43, 67-83. https://doi. org/10.1016/j.trac.2012.12.008.

Iqbal, J., Theegala, C., 2013. Optimizing a continuous flow lipid extraction system (CFLES) used for extracting microalgal lipids. Gcb Bioenergy 5 (3), 327-337. https:// doi.org/10.1111/j.1757-1707.2012.01195.x.
Jesus, M.S., Ballesteros, L.F., Pereira, R.N., Genisheva, Z., Carvalho, A.C., PereiraWilson, C., Teixeira, J.A., Domingues, L., 2020. Ohmic heating polyphenolic extracts from vine pruning residue with enhanced biological activity. Food Chem. 316, 126298. https://doi.org/10.1016/j.foodchem.2020.126298.

Mehta, P., Singh, D., Saxena, R., Rani, R., Gupta, R.P., Puri, S.K., Mathur, A.S., 2018. High-value coproducts from algae - an innovational way to deal with advance algal industry. In: Singhania, R.R., Agarwal, R.A., Kumar, R.P., Sukumaran, R.K. (Eds.), Waste to Wealth. Springer, Singapore, Singapore, pp. 343-363. https://doi.org/ 10.1007/978-981-10-7431-8 15.

Molina-Grima, E., Belarbi, E.H., Acién Fernández, F.G., Robles Medina, A., Chisti, Y., 2003. Recovery of microalgal biomass and metabolites: process options and economics. Biotechnol. Adv. 20 (7-8), 491-515. https://doi.org/10.1016/S07349750(02)00050-2.

Montgomery, D.C., 2017. Design and Analysis of Experiments, 9th ed. John Wiley, New York.

Pagels, F., Guedes, A.C., Amaro, H.M., Kijjoa, A., Vasconcelos, V., 2019. Phycobiliproteins from cyanobacteria: chemistry and biotechnological applications. Biotechnol. Adv. 37, 422-443. https://doi.org/10.1016/j.biotechadv.2019.02.010.

Pagels, F., Lopes, G., Vasconcelos, V., Guedes, A.C., 2020a. White and red LEDs as twophase batch for cyanobacterial pigments production. Bioresour. Technol. 123105. https://doi.org/10.1016/j.biortech.2020.123105.

Pagels, F., Salvaterra, D., Amaro, H.M., Lopes, G., Sousa-Pinto, I., Vasconcelos, V., Guedes, A.C., 2020b. Factorial optimization of upstream process for Cyanobium sp. Pigments production. J. Appl. Phycol. 32 (6), 3861-3872. https://doi.org/10.1007/ s10811-020-02260-8.

Pagels, F., Salvaterra, D., Amaro, H.M., Lopes, G., Sousa-Pinto, I., Vasconcelos, V., Guedes, A.C., 2020c. Bioactive potential of Cyanobium sp. Pigment-rich extracts. J. Appl. Phycol. 32, 3031-3040. https://doi.org/10.1007/s10811-020-02213-1.

Pataro, G., Barca, G.M., Pereira, R.N., Vicente, A.A., Teixeira, J.A., Ferrari, G., 2014. Quantification of metal release from stainless steel electrodes during conventional and pulsed ohmic heating. Innov. Food Sci. Emerg. Technol. 21, 66-73. https://doi. org/10.1016/j.ifset.2013.11.009.

Patil, G., Chethana, S., Sridevi, A.S., Raghavarao, K.S.M.S., 2006. Method to obtain Cphycocyanin of high purity. J. Chromatogr. A 1127, 76-81. https://doi.org/ 10.1016/j.chroma.2006.05.073.

Pereira, R.N., Rodrigues, R.M., Genisheva, Z., Oliveira, H., de Freitas, V., Teixeira, J.A., Vicente, A.A., 2016. Effects of ohmic heating on extraction of food-grade phytochemicals from colored potato. Food Sci. Technol. 74, 493-503. https://doi. org/10.1016/j.lwt.2016.07.074.

Sastry, S.K., Heskitt, B.F., Sarang, S.S., Somavat, R., Ayotte, K., 2014. Why ohmic heating? Advantages, applications, technology, and limitations. In: Sastry, S.K., Abdelrahim, K., Ramaswamy, H.S., Marcotte, M. (Eds.), Ohmic Heating in Food Processing. CRC press, United States, pp. 7-14. https://doi.org/10.1201/b16605.

Shih, S.R., Tsai, K.N., Li, Y.S., Chueh, C.C., Chan, E.C., 2003. Inhibition of enterovirus 71induced apoptosis by allophycocyanin isolated from a blue-green alga Spirulina platensis. J. Med. Virol. 70 (1), 119-125. https://doi.org/10.1002/jmv.10363.

Tola, Y.B., Rattan, N.S., Ramaswamy, H.S., 2014. Electrodes in ohmic heating, in: ohmic heating in food processing. In: Sastry, S., Abdelrahim, K., Ramaswamy, H.S., Marcotte, M. (Eds.), Ohmic Heating in Food Processing. CRC press, United States, pp. 131-140. https://doi.org/10.1201/b16605.

Varghese, K.S., Pandey, M.C., Radhakrishna, K., Bawa, A.S., 2014. Technology, applications and modelling of ohmic heating: a review. J. Food Sci. Technol. 51 (10), 2304-2317. https://doi.org/10.1007/s13197-012-0710-3.

Yodsuwan, N., Kamonpatana, P., Chisti, Y., Sirisansaneeyakul, S., 2018. Ohmic heating pretreatment of algal slurry for production of biodiesel. J. Biotechnol. 267, 71-78. https://doi.org/10.1016/j.jbiotec.2017.12.022.

Zavřel, T., Sinetova, M.A., Červený, J., 2015. Measurement of chlorophyll a and carotenoids concentration in cyanobacteria. Bioprotocol 5 (9), e1467. https://doi. org/10.21769/BioProtoc.1467. 